Korean J Ophthalmol 2020;34(6):498-499 https://doi.org/10.3341/kjo.2020.0053

\section{A Case of Bilateral Iris Involvement of Lymphoma Successfully Managed with Intravitreal Methotrexate In- jection}

\section{Dear Editor,}

Non-Hodgkin lymphoma accounts for approximately $4.2 \%$ of all new cancer cases in the US, and $2.7 \%$ of all cancer-related deaths [1,2]. It has been previously reported that $7 \%$ of systemic lymphomas have ocular involvement [3]. The ocular manifestations of lymphoma may involve the uveal tract, subretinal space, retina, vitreous humor, and aqueous humor. However, the involvement of the iris in lymphoma is rare [4]. To the best of our knowledge, no previous cases of iris involvement in lymphomas have been reported in the Korean population. Here, we describe a Korean patient with iris involvement in non-Hodgkin lymphoma, which was treated with intravitreal methotrexate injections.

A 49-year-old Korean woman presented with recent-onset blurred vision in both eyes (OU). She was on concurrent chemoradiotherapy for cervical cancer and was on triple intrathecal chemotherapy for stage 4B diffuse large B-cell lymphoma (DLBCL) with metastasis to the skin and bone. The patient's best-corrected visual acuity was $20 / 25$ in the right eye (OD) and 20 / 20 in the left eye (OS). Her intraocular pressure (IOP) was $34 \mathrm{mmHg}$ OD and 31 mmHg OS on Goldmann applanation tonometry. There were multiple mutton-fat keratic precipitates, anterior chamber reaction with grade $2+$ cells, and multiple non-pigmented iridal masses in both eyes, more prominent in the left eye (Fig. 1A, 1B). The posterior segments of both eyes were normal. The diagnosis of intraocular uveitis associated with metastasis of lymphoma to the iris was suspected. Anterior chamber paracentesis was performed for cytology. Microscopic examination of the aqueous humor

Received: April 20, 2020 Final revision: August 9, 2020

Accepted: August 24, 2020 sample revealed no evidence of malignancy. The patient was started on $1 \%$ prednisolone acetate eye drops every 2 hours OU and dorzolamide $2 \% /$ timolol $0.5 \%$ combination eye drops and brimonidine $0.2 \%$ eye drops twice a day OU. The patient was followed-up the next day, and her IOPs were still elevated at $34 \mathrm{mmHg}$ OD and $30 \mathrm{mmHg}$ OS. Anterior segment optical coherence tomography demonstrated angle closure due to a mass in the iris (Fig. 1C, 1D). Since we suspected metastasis of a pre-existing systemic lymphoma to the iris, we injected $0.05 \mathrm{~mL}$ of methotrexate $(4 \mathrm{mg} / \mathrm{mL})$ intravitreally in both eyes. Glaucoma medications were added: travoprost $0.004 \%$ eye drops once daily OU and oral acetazolamide $250 \mathrm{mg}$ three times a day with supplementary potassium. Due to uncontrolled ocular hypertension, she underwent iridectomy, biopsy of the iris, anterior chamber irrigation, and aspiration
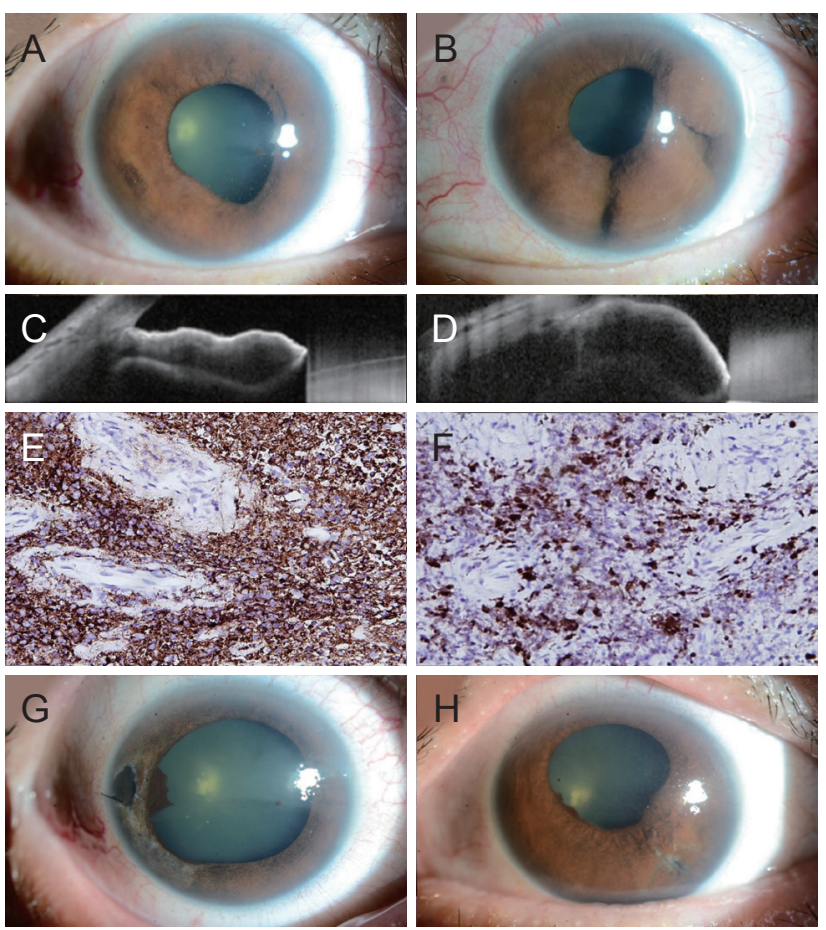

Fig. 1. Photographs of multiple iris lumps in the (A) right and (B) left eye at presentation. Anterior segment optical coherence tomography showing angle closure in the (C) right and (D) left eye. (E) Iris biopsy revealed diffuse degeneration with numerous CD20+ neoplastic B lymphocytes (immunohistochemistry, $\times 200$ ). (F) Cells showed high index of Ki-67 protein. Photographs of resolved iris mass in the $(\mathrm{G})$ right and $(\mathrm{H})$ left eye at the last visit before the transfer. 
for cytology. Histopathologic examination of the iris tissue revealed atypical lymphocytic infiltration with marked degeneration and positive CD20 and Ki-67 protein expression, compatible with DLBCL (Fig. 1E, 1F). The tumor size decreased after the first intravitreal injection of methotrexate and continued to decrease over the course of the treatment. A total of six intravitreal injections were administered: four weekly and two monthly. Three months post-treatment, she was transferred to another hospital for palliative management of cervical cancer progression, then she was lost to follow-up. During the last visit, best-corrected visual acuity (20 / 40 OD and 20 / 30 OS) and IOP were under control, and there was no sign of tumor recurrence until the last follow-up (Fig. 1G, 1H).

In conclusion, this is a case of secondary metastatic recurrence of DLBCL to the iris. Secondary lymphomas of the iris, which are extensions of pre-existing systemic lymphomas, occur more often and tend to be more aggressive than primary ones [5]. Therefore, it is important not to miss the diagnosis of metastasis of systemic lymphomas to the iris. Our patient did not give many helpful clues, such as salmon-colored conjunctival mass, abnormal iris vessels, and hyphema. However, the presence of a mass in the iris and a history of systemic DLBCL were the key to the accurate diagnosis. While most cases of iris lymphomas introduced in the literature were treated with external beam radiotherapy [5], our patient was successfully managed with in the literature methotrexate injections only. The size of the iris mass significantly decreased even with the first injection, and it almost completely disappeared during the three-month treatment. Intravitreal injections of methotrexate might be a reasonable treatment option for cases of iris involvement in systemic lymphoma.

\footnotetext{
Yoon Jeong ${ }^{1,2}$

${ }^{I}$ Department of Ophthalmology, Seoul National University Bundang Hospital, Seoul National University College of Medicine, Seongnam, Korea

${ }^{2}$ Department of Ophthalmology, Seoul National University Hospital, Seoul National University College of Medicine, Seoul, Korea
}

Eun Ji Lee, Se Joon Woo

Department of Ophthalmology, Seoul National University Bundang Hospital, Seoul National University College of Medicine, Seongnam, Korea

E-mail(SeJoonWoo): sejoon1@snu.ac.kr

\section{Conflict of Interest}

No potential conflict of interest relevant to this article was reported.

\section{Acknowledgement}

This work was supported by the National Research Foundation of Korea (NRF) grant funded by the Korea government (MSIT) (No. 2020R1F1A1072795).

\section{References}

1. Evens AM, Blum KA, editors. Non-Hodgkin lymphoma: pathology, imaging, and current therapy. 1st ed. Dordrecht: Springer International Publishing; 2015. p. 2.

2. Parakrama C, Taylor CR. The lymphoid system. II. Malignant lymphomas. In: Parakrama C, Taylor CR, editors. Concise pathology. 2nd ed. Norwalk: Appleton \& Lange; 1995. p. 433-49.

3. Nelson CC, Hertzberg BS, Klintworth GK. A histopathologic study of 716 unselected eyes in patients with cancer at the time of death. Am J Ophthalmol 1983;95:788-93.

4. Velez G, de Smet MD, Whitcup SM, et al. Iris involvement in primary intraocular lymphoma: report of two cases and review of the literature. Surv Ophthalmol 2000;44:518-26.

5. Mashayekhi A, Shields CL, Shields JA. Iris involvement by lymphoma: a review of 13 cases. Clin Exp Ophthalmol 2013;41:19-26. 